\title{
O Petróleo no Senado
}

$665.5(81)$

\author{
Senador Jarbas Maranhão
}

Projeto de Lei do Senado n. ${ }^{\circ} 1$, de 1955 , modifica dispostivos da Lei $n .^{\circ} 2.004$, de 3 de outubro de 1953, que instituiu o monópolio da União em matéria de petróleo e a emprêsa destinada à sua execução, isto é, a $\mathrm{Pe}$ tróleo Brasileiro S.A. - Petrobrás.

De sua justificação se verifica que é propósito fundamental da iniciativa alterar o vigente regime do monopólio, uma vez que as atividades relacionadas com o petróleo poderão vir a ser exercidas por terceiros e não exclusivamente, como na lei em vigor, pela Petrobrás.

Mas há uma contradição flagrante na manifestação dêsse propósito por parte do autor do projeto, quando mantém o artigo 1 . da Lei n. ${ }^{\circ} 2.004$. Não é possivel conciliar o estabelecido no citado dispositivo com a modificação pretendida para o art. $20^{\circ}$. A concessão importa, efetivamente, em quebra do monopólio, que, na lei da Petrobrás, constitui privilégio da Únião, ou, seja, do próprio Estado.

De fato, o art. $10^{\circ}$ da aludida lei diz que constiuem monopólio da União a pesquisa, a lavra, a refinação e o transporte do petróleo e que, para a execução dêsse monópolio, a União disporá de dois órgãos, o Conselho Nacional do Petróleo, para as tarefas de orientação e fiscalização, e a Petrobrás, para a execução. A Petrobrás é, nesse caso, o instrumento executivo de um pri vilégio reservado ao Estado.

Ora, de acôrdo com o projeto, as atividades poderão vir a ser exercidas por nacionais ou emprêsas organizadas de acôrdo com as nossas leis, que passarão a competir com a emprêsa criada pelo Estado, não havendo mais, portanto, monopólio. O conceito de monopólio exclui o de multiplicidade de agentes e o de competição. Os próprios autores do projeto assinalam êsse ponto quando, em certo trecho da justificação, dizem que existe monopólio quando é dado a alguém, «sem competidor, explorar uma indústria ou vender uma mercadoria especial».

Além disso, precisamos ter em vista que o monopólio estabelecido na Lei n..$^{\circ}$ 2.004 não se restringe ao aspecto da propriedade do subsolo. Ao contrário, o monopólio foi mesmo estabelecido para compreender as diversas fases da indústria petrolifera, desde a pesquisa e a extração de óleo cru de jazida ou de xisto até a refinação e o transporte. À iniciativa privada foram deixadas, livremente, mas dentro, é claro, de outras leis pertinentes à matéria, a distribuição e venda dos produtos acabados aos consumidores e as cha- 
madas indústrias petroquímicas, que utilizam como matéria prima os subprodutos da refinação.

A lei estabeleceu um sistema orgânico de exploração do petróleo no país. O projeto procura substituir êsse sistema por um regime de concessões, sem definir as condições precisas em que as mesmas devem ser outorgadas e sem precisar a situação real em que ficará a Petrobrás após êsse novo regime. Ela, a Petrobrás, está excluida do rol dos concessionarios.

Mas que seria a Petrobrás, na forma do projeto? Teria regime de privilégios especiais que a defendesse dos concorrentes ? Não, o projeto não lhes atribui êsses elementos de defesa. O projeto a coloca, então, em condições de igualdade com os futuros concessionários? Também não, mas pior até. Realmente, a Petrobrás, que, no regime vigente, tem a exclusividade para pesquisar, produzir, industrializar e transportar petróleo, ver-se-ia em situação de extrema inferioridade em relação àos prováveis e futuros concessionários, em face da nova redação proposta para o parágrafo único do art. 6\%, da Lei $n^{\circ} 2.004$.

De fato. A pesquisa e a, lavra pela Petrobrás ficariam limitadas à área do Recôncavo baiano e as áreas formadas por um raio de 22 quilômetros «tendo como centro um poço pioneiro de produção comercial, que tenha sido perfurado antes da vigência desta lei». Isto importa em dizer que, na situação atual, fora do Recôncavo baiano, a Petrobrás só poderia pesquisar numa pequena área de 152.000 hectares, em tôrno do poço de Nova Olinda, enquanto qualquer concesisonário poderia obter áreas de até 600.000 hectares para pesquisa e lavra em qualquer ponto do território nacional, inclusive em tôrno do Recôncavo baiano e de Nova Olinda.

O projeto é, portanto, profundamente prejudicial à Petrobrás.

Quanto ao tumulto que o presente projeto traria à organização legal do problema do petróleo entre nós, não há a menor dúvida. Sob êsse aspecto, êle é decisivamente perturbador. Constitui-se num impacto de repercussões imprevisiveis no tratamento da questão, de vez que concorre para para confundir a terminologia, subverter conceitos e acrescentar obscuridades onde a lei vigente é clara e sistemática. E para uma mudança tão radical na orientação juridica da matéria, seria necessário que se houvesse cuidado de revesti-lo de coerência e precisão.

Realmente, para problema de tal complexidade e sujeito a tantas controvérsias, conveniente seria conceituar rigorosamente os objetos e definir com propriedade as relações juridicas. Para referir sòmente a questão da indeterminação de conceitos que o projeto encerra, basta mencionar as impropriedades, expressões equívocas e deficiências técnicas com que são empregados têrmos como monopólio, explorar poço pioneiro de produção comercial, preço internacional de óleo cru e derivados e outros mais que ressaltaria a uma leitura atenta.

Não se fica sabendo se monopólio continua a ser aquilo que o art. $1 .^{\circ}$, da Lei $n^{\circ} 2.004$, estabelece, ou se corresponde ao expresso desejo do projeto de que o tratamento do problema e o exercício das atividades sejam divididos por muitos. Não se fica sabendo se explorar é empregado na acepção de pes- 
quisar, procurar no desconhecido, ou se na de extrair petróleo do subsolo. Não se pode atinar com o que se pretende através de expressão equivoca como poço pioneiro de produção comercial. Os poços pioneiros, por definição, ainda não se classificam entre os de produção comercial, são poços de pesquisas; os poços de produção comercial já não se encontram mais entre os considerados pioneiros, pertencem a uma etapa ulterior da produção petrolifera. Quanto à exigência de entrega do petróleo (não se sabe bem a quem) pelo preço internacional, ainda maior a confusão. Primeiramente, porque não há um preço internacional para o óleo cru e cada derivado, mas preços distintos para cada tipo e qualidade e em cada ponto de embarque. Além do mais, mesmo que houvesse êsse preço, isso seria uma inovação total, uma subversão na política de preços do govêrno, inclusive por subjugá-la ao mercado internacional, em vez de a fundamentar nos custos efetivos de produção, no país.

Em suma, o projeto pretende substituir uma situação definida por uma situação caótica, inclusive sob o aspecto jurídico.

Por conseguinte, mesmo que - para argumentar - pelo mérito o prujeto não merecesse a rejeição do Senado, pelos seus aspectos técnicos-formais seria em todo sentido desaconselhável, pois fundamentalmente interessam a normalidade, a coerência, e a integridade da lei. Se esta, por ventura, já não atendesse às exigências da realidade, que fôsse substituída, mas por outra lei que servisse a essa mesma realidade e não concorresse para distanciar os instrumentos de ação legal da realidade viva.

Mas, se fôsse sòmente isso não seria tanto. $\mathrm{O}$ que realmente o projeto atinge são direitos da União, dos Estados, do Distrito Federal e dos Municipios. Quanto aos da primeira, ainda se poderá alegar que a ela mesma compete dispor sôbre o que lhe diz respeito. Mas no que tange aos direitos de acionistas como os Estados, o Distrito Federal e os Municípios, o projeto é simplesmente lesivo. Atentemos para o fato de que essas entidades públicas da federação se tornaram acionistas obrigatórias da Petrobrás, em virtude do que dispõem as Leis ns. 1.749, de 28-11-52, e 2.004, de 3-10-53. Recursos que lhes pertenciam e pertencem, oriundos do impôsto único sôbre derivados de petróleo, e antes totalmente destinados a obras rodoviárias, foram vinculados à Petrobrás. Automàticamente, $25 \%$ da arrecadação do referido tributo são depositados no Banco do Brasil pelas Alfândegas, para ocorrer à integralização do capital mínima de 10 bilhões de cruzeiros. A esta altura, a $\mathrm{Pe}$ trobrás, já não é apenas uma entidade do govêrno federal, mas uma emprêsa nacional, de capital misto, na qual grandes recursos que não pertencem à União foram incorporados a título de subscrição de capital. A primeira distribuição de ações ordinárias da Companhia dar-se-á pròximamente, e cêrca de 1 bilhão e 245 milhões de cruzeiros dos Estados, do Distrito Federal e dos Mun cipios lhes serão devolvidos em ações ordinárias.

Como admitir-se, pois, mudança tão profunda na orientação legal, sem que ao menos se prevejam as indispensáveis compensações financeiras às referidas entidades de direito público? É sensato admitir-se que o govêrno federal as tenha convocado para participar de um empreendimento de grande vulto, com magníficas perspectivas de sucesso e lucro, com inteira e completa 
jurisdição sôbre todo o território nacional, depois, sem maiores razões ou fundamentos restrinja as atividades da emprêsa e, conseqüentemente, as suas possibilidades de sucesso, lucro e poderio?

Interessará ao Rio Grande do Sul, a Goiás, a Minas Gerais, a São Paulo, a Pernambuco, ao Paraná, e a todos os demais Estados e respectivos Municípios participar obrigatòriamente de uma emprêsa cujas atividades ficarão pràticamente limitadas ao Recôncavo baiano e a uma área de 152.000 hectares em Nova Olinda, quando por lei participam de uma emprêsa cuja ação tende a se estender e a se expandir por todo o território nacional, onde houver petróleo, e sem competidor?

Qual a justificação que o projeto oferece para tamanha mudança? Nenhuma. Repisa velhos e superados argumentos em tôrno do problema do petróleo entre nós. Reedita emenda que o Congresso Nacional rejeitou quando da discussão da lei. Refere-se a recursos, quando êsses recursos, após uma luta incessante, puderam ser assegurados à Petrobrás, inclusive em dólares, conforme resolução de 3 de fevereiro último do Conselho de Superintendência da Moeda e do Crédito. Refere-se à carência de técnicos e aparelhamentos, quando é sabido e não paira a menor dúvida quanto à inteira liberdade da Petrobrás para contratar os serviços dos melhores técnicos e para adquirir os mais modernos equipamentos especializados.

Pois bem. A União, os Estados, o Distrito Federal e os Municípios são sócios dêsse empreendimento, cujo sucesso dia a dia se afirma aos olhos da Nação. Que pretende o projeto fazer dessa sociedade? Transformá-la numa emprêsa de segunda ou terceira categoria, por julgá-la ineficiente? Não há elementos de prova para que o Poder Legislativo o faça.

Assim vejamos, de acôrdo com dados que nos foram fornecidos por técnicos da Petrobrás:

A lei n. 2.004, de 3 de outubro de 1953, que resultou de um debate extenso e profundo - talvez o mais amplo e demorado debate sôbre problema econômico brasileiro - a respeito da experiência nacional em matéria de politica petrolifera, não foi sequer posta à prova. A execução do programa do petróleo, através da Petrobrás, como estabeleceu aquela lei, cobre pràticamente um periodo de 7 meses, pois sòmente a partir de $10^{\circ}$ de agôsto de 1954 os serviços de exploração e produção de óleo cru passaram à administração da emprêsa.

Um semestre de atividade não oferece bases nem justificativa para revisão de uma lei, elaborada após árduos estudos, e que não foi experimentada ainda em todos os seus aspectos. Sòmente um fato de suma gravidade poderia admitir a possibilidade de se procurar uma nova orientação legal. Mas, pelo menos por enquanto, não se indicam ocorrências que enfraqueçam ou abalem os fundamentos adotados; ao contrário, a intensificação das atividades do programa do petróleo, apesar de curto prazo decorrido, é argumento ponderável em favor da continuidade daiorientação tão recentemente inaugurada.

Com efeito, de agôsto até esta parte, muitos fatos podem ser mencionados como indicativos do acêrto da orientação atual. Dois fatos culminantes: a) o êxito da Refinaria de Cubatão, que ainda em sua fase experimental, está pro- 
cessando óleo além de sua capacidade nominal, isto é, 50.000 barris por dia; b) o êxito das explorações da Amazônia com a localização de um campo produtor em Nova Olinda de possibilidades promissoras, logo na primeira sondagem .

Além dêsses acontecimentos de alta significação, poderíamos citar ainda:

$$
\text { No setor exploração }
$$

$1 .^{\circ}$ elevação das reservas de óleo do Recôncavo baiano, com a recuperação do campo de Dom João, submetido a regime de injeção de gás e água;

$\left.2 .^{\circ}\right)$ perfuração de poços submarinos pela primeira vez no Brasil, com pleno êxito;

3.) contrato de eminente técnico para a Chefia do Departamento de Exploração;

$\left.4 .^{\circ}\right)$ «record» nas atividades de perfuração no Brasil, com u'a média de agôsto a dezembro, de quase 5.000 metros mensais com o mesmo equipamento já existente, isto é, 2,5 vêzes o ritmo de perfuração em 1951, por exemplo.

\section{No setor produção}

1. ${ }^{\circ}$ no periodo agôsto a dezembro a produção atingiu uma média mensal de 110.000 barris, ou seja, o dôbro da produção em 1951 e do I semestre de 1954;

$2 .^{\circ}$ ) os campos baianos estão aptos a produzirem já mais de 6.000 barris por dia, podendo ser elevada essa capacidade, em futuro próximo;

$\left.3 .^{\circ}\right)$ a produção de gás natural é 10 vêzes superior à média de 1951 e $28 \%$ à do I semestre de 1954 .

\section{No setor refino}

1..$^{\circ}$ a Refinaria de Mataripe processou, de agôsto a dezembro, uma quantidade de óleo $48 \%$ superior à do I semestre de 1954 e 2,2 vêzes à de 1951;

2. ${ }^{\circ}$ os estudos para ampliação dessa Refinaria, para 15.000 barris diários, com uma unidade de lubrificantes, estão em fase bastante adiantada.

Enfim, uma revisão da politica atual significaria um pronunciamento ou um julgamento da Petrobrás pelo Poder Legislativo, sem suficientes elementos para julgá-la, muito menos ainda neste momento.

A inoportunidade, além do mais, evidencia-se pelos reflexos psicológicos que uma revisão da politica atual provocaria, afetando o crédito da emprêsa no exterior e mesmo no país. Sempre que se verificam manifestações de apoio por parte dos Podêres da República em relação à Petrobrás ou são adotadas medidas práticas tendentes a favorecer suas atividades, como no caso de recente resolução da SUMOC, a emprêsa encontra facilidades em negociar, in- 
clusive financiamentos, quer no pais quer no exterior. Mas, quando são levantadas dúvidas ou não tentadas revisões, a Petrobrás sente-se imediatamente dificultada em sua ação pelas precauções, às vêzes excessivas dos que com ela transacionam.

Pondo à margem outros aspectos juridicos do projeto, em relação, por exemplo, à própria soberania nacional, e fazendo abstração de seu mérito, pensamos que deve sel rejeitado, por ser incompativel com o sistema adotado na lei, inconveniente e inoportuno, prejudicial à Petrobrás, lesivo ao patrimônio e aos interêsses da União, dos Estados, do Distrito Federal e dos Municípios, e por conter falhas de técnica legislativa. 